BioScience Trends. 2019; 13(5):E1.

DOI: $10.5582 /$ bst.2019.E1

\title{
RETRACTED: Polyphosphate-induced matrix metalloproteinase-3-mediated differentiation in rat dental pulp fibroblast-like cells.
}

This article entitled "Polyphosphate-induced matrix metalloproteinase-3-mediated differentiation in rat dental pulp fibroblast-like cells" (1) has been retracted at the request of the authors due to research misconduct.

\section{Reference}

1. Hiyama T, Ozeki N, Hase N, Yamaguchi H, Kawai R, Kondo A, Mogi M, Nakata K. Polyphosphate-induced matrix metalloproteinase-3-mediated differentiation in rat dental pulp fibroblast-like cells. Biosci Trends. 2015; 9(6):360-366. 